\title{
José Luis de la Granja (coord.), La España del siglo $X X$ a debate. Homenaje a Manuel Tuñón de Lara. Madrid: Tecnos, 2017, 438 págs.
}

La cantidad de publicaciones y homenajes existentes sobre la figura de Manuel Tuñón de Lara es sintomática de la posición que este historiador ocupa en la memoria profesional de la historiografía española, similar a la de nombres tan significativos como los de Jaume Vicens Vives o Pierre Vilar. Aunque el primer homenaje a Tuñón se llevó a cabo en una fecha tan temprana como 1981, ha sido desde los años noventa del pasado siglo, y especialmente tras su fallecimiento en 1997, cuando se han sucedido todo tipo de estudios en su memoria por parte de discípulos, colegas y amigos. En un momento en el que además la historiografía española se situaba ante un nuevo horizonte de desarrollo, estas publicaciones contribuyeron a difundir una imagen simbólica de Tuñón, como un personaje que marcó el naciente contemporaneísmo de los años del tardofranquismo y la Transición, habida cuenta el atractivo que ejercía su imagen de intelectual antifranquista exiliado en Francia, la enorme difusión de sus obras pioneras sobre la España contemporánea, y el papel de los célebres Coloquios de Pau reunidos bajo su magisterio. En líneas muy generales, este es el retrato de Tuñón de Lara que permanece en la historiografía española en la actualidad.

La España del siglo XX a debate es el último ejemplo de esta dilatada labor memorialista, en esta ocasión con motivo del vigésimo aniversario de la muerte de Manuel Tuñón de Lara. Que el coordinador de la obra sea José Luis de la Granja, y que la gran mayoría de los autores convocados sean habituales, y/o animadores, de muchos de los anteriores homenajes, es un claro síntoma de su voluntad de continuidad con este anterior espíritu de reconocimiento del que hablábamos. Más concretamente, con dos publicaciones tan relevantes como fueron Manuel Tuñón de Lara. El compromiso con la Historia. Su vida y su obra, y Tuñón de Lara y la historiografía española, un hecho del que de la Granja deja constancia en el prólogo. ${ }^{1}$ La referencia a estas obras, además, permite justificar la división de este nuevo homenaje en dos partes claramente diferenciadas: una primera que pasa revista a la historiografía española dedicada al siglo XX, en alusión a La España del siglo XX de Tuñón, y en la línea de una tradicional preocupación por el balance historiográfico que podríamos retrotraer hasta el $\mathrm{X}$ Coloquio de $\mathrm{Pau}^{2}$ y una segunda que reúne distintos estudios, semblanzas y documentos relacionados ya más directamente con la obra y trayectoria vital y académica de Manuel Tuñón de Lara.

Esta revisión inicial de la historiografía del siglo XX, agrupada por periodos, supone una útil guía para orientarse sobre el estado de la investigación española en este ámbito, si bien desde muy distintos puntos de vista. Allí nos podemos encontrar, por ejemplo, ante balances y comentarios bibliográficos más clásicos, como los que Ángel Viñas y Glicerio Sánchez Recio dedican a áreas como la Guerra Civil o el Franquismo.

\footnotetext{
${ }^{1}$ José Luis de la Granja y Alberto Reig Tapia (eds.), Manuel Tuñón de Lara. El compromiso con la Historia. Su vida y su obra (Bilbao: Universidad del País Vasco, 1993), y José Luis de la Granja, Alberto Reig Tapia y Ricardo Miralles (eds.), Tuñón de Lara y la historiografía española (Madrid: Siglo XXI, 1999).

2 Manuel Tuñón de Lara, Historiografía española contemporánea. X Coloquio del Centro de Investigaciones Hispánicas de la Universidad de Pau. Balance y resumen (Madrid: Siglo XXI, 1980).
} 
El primero muestra una historiografía en expansión, capaz de renovar cuestiones e interpretaciones, y hacer frente a nuevos mitos y falsedades heredadas en las sucesivas actualizaciones de lo que denomina como canon franquista sobre la Guerra Civil. Con todo, Viñas centra su comentario en campos afines a sus propias investigaciones: los antecedentes de la guerra, la figura de Franco, la relación de los líderes republicanos con la Unión Soviética, y el contexto internacional de la Guerra Civil. En el caso de Sánchez Recio, tras repasar la interpretación de Tuñón sobre la dictadura de Franco y la situación del ya clásico debate sobre la naturaleza del estado franquista, dedica buena parte de su artículo a comentar los temas y géneros historiográficos más relevantes de la investigación sobre el periodo franquista - esto es, la violencia y represión política, el exilio, la economía, el clero, la oposición antifranquista, las biografías de Franco y las obras de síntesis-.

Otro tipo de trabajos sin embargo, combinan el repaso bibliográfico con el análisis y la reflexión historiográfica. Este sería el caso de Manuel Sánchez Cortina y su examen sobre la más reciente investigación dedicada a la Restauración. Para este, es constatable una especial renovación en dicho campo de estudios durante las dos últimas décadas, apreciable en su nueva valoración en términos de modernidad, en la proliferación de estudios comparativos que sitúan la Restauración en el contexto de la Europa meridional, y en el giro culturalista experimentado hacia cuestiones como las identidades o las culturas políticas. Los tres elementos serían, según Suárez Cortina, una consecuencia de la propia evolución, modernización y normalización de la historiografía española en todo este tiempo. Mención especial merece el exhaustivo y amplio análisis de Eduardo González Calleja sobre la historiografía política de la II República. En líneas muy generales, este trabajo examina las controversias y debates que han marcado el análisis político de la II República a la luz de dos grandes paradigmas interpretativos: el síndrome del fracaso de la experiencia republicana, que para González Calleja ha conocido distintas versiones en la historiografía franquista, la propia memoria de los vencidos, la historiografía liberal-conservadora anglosajona, el neofranquismo y el revisionismo académico; y el paradigma de la frustración, que más centrado en los problemas y dificultades del reformismo republicano, ha sido la base de la investigación más destacada llevada a cabo desde los años setenta. Evidentemente, no es este el lugar para entrar a analizar la variedad de perspectivas que analiza este trabajo sobre cuestiones como la reforma agraria, los actores políticos, las estrategias política de la CNT o el PSOE, la naturaleza del fascismo español o de la CEDA, o la violencia sociopolítica y su relación con el tema de las causas de la guerra, entre otras. Pero sí que nos interesa destacar cómo González Calleja percibe en el revisionismo académico -que caracteriza como una derivación de las interpretaciones liberales anglosajonas surgida en los conflictos memoriales de los años noventa, con apariencia de tercera vía entre las interpretaciones progresistas y el negacionismo neofranquista-, una importante fuente de controversias. De hecho, en última instancia, este artículo de González Calleja se puede interpretar como una toma de posición crítica frente a la metodología e interpretaciones difundidas por este revisionismo académico en los últimos veinticinco años, que se inserta además dentro del reciente debate sobre el revisionismo surgido en el seno de la historiografía española.

Esta mirada a la historiografía sobre el siglo XX participa tanto de las características como de la importancia del género de los balances bibliográficos o 
estados de la cuestión, tan necesarios como poco frecuentes: ofrece una fotografía general sobre la situación de la investigación, nos ayuda a detectar novedades y lagunas, o a percibir y clarificar debates, interpretaciones y polémicas, etc. Pero más allá del contenido e interés de cada estudio, y de que se pueda echar de menos el tratamiento específico de algunas temáticas al optar por el agrupamiento en periodos históricos, uno de los grandes activos de la obra que nos ocupa reside en su valor comparativo con el balance realizado en 1999 en Tuñón de Lara y la historiografía española. La visión de ambas publicaciones en conjunto constituye un buen ejercicio para distinguir algunos de los cambios, novedades y características del desarrollo de la historiografía española en el siglo XXI, si bien de forma parcial y tan solo en lo que respecta a la investigación volcada hacia el siglo XX.

Dos campos de estudio hoy tan relevantes como los nacionalismos o la Transición, que en este volumen abordan Juan Sisinio Pérez Garzón y Santos Juliá, no aparecían contemplados en 1999, y reflejan cómo la historiografía española ha respondido ante los debates, conflictos y problemáticas políticas y sociales de la España del siglo XXI. Tanto Pérez Garzón como Juliá, además, se desmarcan del mero balance bibliográfico con estudios de mayor recorrido, que en última instancia remiten a la siempre difícil relación entre la historiografía y los usos políticos de la historia. Juan Sisinio Pérez Garzón por ejemplo, comprende la reciente historiografía sobre los nacionalismos desde la permanente dialéctica entre el estudio de la singularidad nacional y la necesidad de una metodología científica para llevarlo a cabo, y desde los retos planteados por la evolución de los idearios y programas historiográficos del nacionalismo español, catalán, vasco y gallego en los siglos XIX y XX. Percibe asimismo las causas políticas e historiográficas por las que el estudio de la cuestión nacional se ha convertido en el tema estrella de la historiografía española de los últimos veinte años. Y a partir de aquí, este historiador nos muestra un interesante análisis comparativo de las principales obras y problemáticas a las que han respondido las historiografías de los nacionalismos, siempre en relación con los conflictos identitarios de principios del siglo XXI: desde las publicaciones más significativas acerca del nacionalismo español, que han contribuido a reinterpretar la construcción del Estadonación desde 1995, pero que también han provocado la respuesta de una serie de autores que niegan el proceso constructivo de la nación española y su reducción a una invención del siglo XIX; a la incidencia en la historiografía del desarrollo del nacionalismo catalán y las distintas perspectivas existentes sobre la cuestión nacional catalana, un hecho que habría desembocado en la existencia de líneas interpretativas contrapuestas entre la desmitificación del nacionalismo teleológico y la justificación de la identidad catalana a lo largo de la historia; pasando por la historiografía del nacionalismo vasco, capaz de hacer frente a las narrativas y manipulaciones en torno a la identidad vasca, o la dualidad de la historiografía gallega, dividida entre una historia nacional en la línea de la tradición romántico-liberal, y aquella que estudia facetas de su historia como parte de la historia española o universal.

El objetivo de Santos Juliá, por otro lado, es mostrar cómo la Transición ha sido desde sus inicios una gran cantera de recursos para los usos políticos interesados, que ha producido distintas miradas en función de los contextos históricos en que se han desarrollado. Santos Juliá se refiere a la imagen modélica de la Transición construida al compás de la consolidación democrática, y que vino a desplazar a una visión 
desencantada que la había acompañado desde sus principios, a aquella que comenzó a ver la Transición como un tiempo de silencio y olvido ya en los años noventa, y a las distintas percepciones derivadas de su conversión en campo de batalla ideológico desde el que juzgar los problemas resultantes de la crisis económica y social más reciente. Llegados a este punto, es fácil percibir que este ensayo de Santos Juliá no es un estado de la cuestión propiamente dicho. Sin embargo, sí que se puede leer como una crítica a los usos políticos de la historia desde el presente, y un ejemplo de reacción desde la historiografía a un problema de actualidad en la opinión pública. Todavía es más, se podría decir que en esta toma de postura, Santos Juliá viene a coincidir con las conclusiones sobre la responsabilidad social de los historiadores establecidas por Juan Sisinio Pérez Garzón en su artículo anterior. Sin ir más lejos, dice Pérez Garzón:

\begin{abstract}
En definitiva, tenemos que ser conscientes de las implicaciones sociales y éticas de la ciencia histórica. Ahora bien, la razón histórica ni sirve para maldecir el pasado ni para predecir el futuro, sino que debe facilitar la comprensión de los factores que albergan cada fenómeno social. Para tal fin es insoslayable establecer un parapeto crítico contra las fetichizaciones del pasado, sean de uno u otro signo político, ideológico o religioso, en cualquiera de sus dimensiones (p. 51).
\end{abstract}

Como ya hemos apuntado, la segunda parte de La España del siglo XX a debate cambia totalmente de registro para centrarse en la figura de Tuñón de Lara. Como suele ser habitual en los homenajes académicos, también aquí nos encontramos ante una heterogénea compilación de estudios y semblanzas en memoria de Tuñón -a la que se añade su bibliografía, y la transcripción de los programas en los que este participó en "Radio París" entre 1961 y 1964-. Esta característica es apreciable desde un principio: si Joseph Pérez dibuja una breve pero elogiosa impresión de su figura, como alguien ajeno a las modas que venían de París, fiel a la forma de concebir la historia de sus maestros Núñez de Arenas y Pierre Vilar, José Álvarez Junco por el contrario examina de forma algo más crítica su metodología y visión totalizante de la historia. Tanto es así, que para Álvarez Junco Tuñón no hizo una aportación excesivamente original en el terreno metodológico, sino que su deuda con un "marxismo modernizado por la escuela de los Annales", y su consecuente preocupación por las estructuras, lo colectivo y las relaciones de poder, hicieron que quedara muy pronto superado por el avance de la investigación. Justo a continuación, Ángeles Barrio nos conduce ante una perspectiva muy diferente. Su artículo no versa específicamente sobre la obra o trayectoria de Tuñón, sino que utiliza la defensa de la historia del movimiento obrero que este hizo todavía al final de su vida académica, para analizar la historia social española desde un enfoque algo más amplio. Desde esta perspectiva, Barrio estudia de forma comparativa los distintos orígenes de la historia social española en Estados Unidos, Francia, Inglaterra y España, para después presentar un positivo balance de la renovación y actualización producida en la historia social en España en las últimas décadas, a pesar de las difíciles condiciones de las que partía.

En definitiva, el estudio de contenido más biográfico con el que nos encontramos lo escribe José Luis de la Granja, quien vuelve a abordar la relación entre Max Aub y Tuñón de Lara, para descubrirnos en esta ocasión sus diferencias de opinión sobre la editorial Ruedo Ibérico, y las causas políticas y personales de los recelos de Tuñón hacia dicha editorial, y hacia José Martínez en particular. Dicho trabajo, además de acercarnos al Tuñón más militante, nos sitúa ya en sintonía con el conjunto de 
recuerdos, reflexiones y anécdotas que Paul Aubert, Jean Michel Desvois, Eloy Fernández Clemente, Alberto Reig Tapia y Carmelo Garitaonandia exponen sobre su relación personal con Manuel Tuñón de Lara. En líneas generales, estos trabajos trazan una panorámica de contenido memorial, a cargo de personajes que entraron en contacto con Tuñón desde diferentes posiciones, y en distintos momentos de su vida. Su mayor interés radica, en consecuencia, en lo que estos testimonios puedan aportar al conocimiento de las problemáticas que rodean el análisis de la figura de Tuñón, o incluso a las propias trayectorias de sus autores dentro de la evolución de la historiografía o cultura de las últimas décadas. Aubert y Desvois por ejemplo, dos de los hispanistas franceses más cercanos a Tuñón, aprovechan la ocasión para recordar cómo entraron en contacto con él en la segunda mitad de los años sesenta, y la importancia que conceden a su magisterio, capacidad relacional y calidad humana en su formación como hispanistas. Es sin embargo Aubert, quien también acaba de redactar por cierto un estudio introductorio a la reedición de Medio siglo de cultura española, quien se extiende algo más en su análisis. ${ }^{3}$ Además de repasar la trayectoria biográfica de Tuñón en Francia y su colaboración con la revista católica Esprit, o criticar cómo en Pau se dejó perder su legado, Aubert incide en las razones del atractivo que Tuñón ejercía para él y para la generación de hispanistas que se estaba formando en aquellos momentos: ofrecía un programa de historia de España de los siglos XIX y XX basado en el estudio del movimiento obrero, la prensa, el poder y las elites -la aportación más relevante de Tuñón según Aubert-, y la cultura, en el que estaba todo por hacer; presentaba una visión global de la historia actualizada por el marxismo, que enseñaba a no olvidar las interrelaciones entre los fenómenos; y había creado un espacio de encuentro pluridisciplinar entre los jóvenes hispanistas y sus colegas españoles que tendría grandes consecuencias. Desde esta perspectiva, no es extraño que Aubert acabe por reivindicar enseñanzas de Tuñón como la investigación basada en la crítica de fuentes, el estudio de las interacciones e influencias recíprocas, y la multiplicación de puntos de vista. Para este hispanista, estas ideas todavía están vigentes a la hora de afrontar problemas como la fragmentación del hispanismo francés, la generalización de los estudios sobre la representación que acaban por olvidar la realidad salida de los archivos, o la situación de la enseñanza de las humanidades en la Universidad actual.

Las semblanzas de Eloy Fernández Clemente, Alberto Reig Tapia y Carmelo Garitaonandia, nos emplazan mientras tanto ante el punto de vista de la relación de Tuñón con la historiografía española. Es verdad que Garitaonandia puede parecer algo más ajeno a la trayectoria de Tuñón. Pero el texto de Eloy Fernández Clemente, extraído de sus memorias sobre Andalán, nos da la visión del profesor que entró en contacto con él en el contexto de los Coloquios de Pau, y que a golpe de recuerdos y correspondencia privada, revisa una larga amistad trufada de anécdotas personales en torno a coloquios, proyectos, publicaciones, y a las peripecias profesionales y personales por las que pasó Tuñón en los últimos tiempos de Pau y en España. ${ }^{4}$ Y Alberto Reig Tapia explica en su escrito por qué eligió la Universidad de Pau y a Tuñón de Lara a la hora de solicitar una beca del gobierno francés, y el papel fundamental que desempeñó Tuñón, además de Tierno Galván, para conducir a buen término una investigación sobre la Guerra Civil

\footnotetext{
${ }^{3}$ Paul Aubert, "Manuel Tuñón de Lara y las condiciones de una historia de la cultura", en Manuel Tuñón de Lara, Medio siglo de cultura española (1885-1936) (Pamplona: Urgoiti, 2018), XI-CX.

${ }^{4}$ Eloy Fernández Clemente, Los años de Andalán. Memorias (1972-1987) (Zaragoza: Rolde de Estudios Aragoneses, 2013).
} 
que en España todavía se topaba ante importantes impedimentos. Es decir, aunque ambos autores también se explayan en cuestiones de la trayectoria vital de Tuñón en la España democrática - por ejemplo, Reig Tapia recuerda con tristeza cómo Tuñón quedó afectado por las críticas dirigidas a la serie documental sobre la Guerra Civil emitida en 1986, y en la que los dos habían colaborado-, sus testimonios vuelven a incidir en esta imagen de Tuñón como creador de un espacio de libertad durante los años setenta especialmente, en contraste con la situación que se vivía en España.

Así pues, a medio camino entre el ensayo de egohistoria y la investigación, el tono apologético y el estudio crítico, el descubrimiento de nuevos datos sobre Tuñón y la reproducción de imágenes conocidas, estos análisis anteriores nos conducen una vez más ante las funciones y características retrospectivas de los homenajes académicos, una cuestión siempre compleja y difícil de analizar. Más allá de esta circunstancia, sin embargo, podemos decir que La España del siglo XX a debate es el último ejemplo de una larga tradición de homenajes en memoria de Tuñón de Lara, que al tiempo que presenta un balance sobre la historiografía del siglo XX de gran utilidad, consolida la imagen sobre su figura e importancia establecida en los años noventa. Por lo demás, el carácter generacional de esta obra -hay que tener en cuenta que la mayoría de autores nacieron entre los años 40 y 50 del pasado siglo, y son personajes relevantes en el mundo académico y en el desarrollo de la historiografía contemporánea española-, nos lleva también a preguntarnos cuál es el significado de Tuñón de Lara entre las generaciones de historiadores posteriores, especialmente para aquellos que no lo conocieron. Desde esta perspectiva, quizás haya llegado el momento de que todo el conjunto de publicaciones existente sobre Tuñón, pueda ser utilizado para plantear nuevas aproximaciones a su trayectoria en relación con cuestiones como el exilio y sus retornos, las culturas del antifranquismo, y la evolución de la historiografía y cultura española en los años del tardofranquismo, la Transición, y la primera etapa democrática.

Óscar Adell Ralfas

Universidad de Zaragoza

oadellralfas@gmail.com

Fecha de recepción: 12 de agosto de 2018.

Fecha de aceptación: 16 de septiembre de 2018.

Publicación: 31 de diciembre de 2018.

Para citar este artículo: Óscar Adell Ralfas, "José Luis de la Granja (coord.), La España del siglo XX a debate. Homenaje a Manuel Tuñón de Lara. Madrid: Tecnos, 2017, 438 págs.”, Historiografías, 16 (julio-diciembre, 2018): 151-155. 